\title{
Maternal multimorbidity during pregnancy and after childbirth in women in low- and middle-income countries: a systematic literature review
}

\author{
Mary McCauley ${ }^{1 *}$ (D), Shamsa Zafar ${ }^{2}$ and Nynke van den Broek
}

\begin{abstract}
Background: For every maternal death, 20 to 30 women are estimated to have morbidities related to pregnancy or childbirth. Much of this burden of disease is in women in low- and middle-income countries. Maternal multimorbidity can include physical, psychological and social ill-health. Limited data exist about the associations between these morbidities. In order to address all health needs that women may have when attending for maternity care, it is important to be able to identify all types of morbidities and understand how each morbidity influences other aspects of women's health and wellbeing during pregnancy and after childbirth.
\end{abstract}

Methods: We systematically reviewed published literature in English, describing measurement of two or more types of maternal morbidity and/or associations between morbidities during pregnancy or after childbirth for women in lowand middle-income countries. CINAHL plus, Global Health, Medline and Web of Science databases were searched from 2007 to 2018. Outcomes were descriptions, occurrence of all maternal morbidities and associations between these morbidities. Narrative analysis was conducted.

Results: Included were 38 papers reporting about 36 studies (71,229 women; 60,911 during pregnancy and 10,318 after childbirth in 17 countries). Most studies (26/36) were cross-sectional surveys. Self-reported physical ill-health was documented in 26 studies, but no standardised data collection tools were used. In total, physical morbidities were included in 28 studies, psychological morbidities in 32 studies and social morbidities in 27 studies with three studies assessing associations between all three types of morbidity and 30 studies assessing associations between two types of morbidity. In four studies, clinical examination and/or basic laboratory investigations were also conducted. Associations between physical and psychological morbidities were reported in four studies and between psychological and social morbidities in six. Domestic violence increased risks of physical ill-health in two studies.

Conclusions: There is a lack of standardised, comprehensive and routine measurements and tools to assess the burden of maternal multimorbidity in women during pregnancy and after childbirth. Emerging data suggest significant associations between the different types of morbidity.

(Continued on next page)

\footnotetext{
* Correspondence: mary.mccauley@|wh.nhs.uk

${ }^{1}$ Centre for Maternal and Newborn Health, Liverpool School of Tropical

Medicine, Pembroke Place, Liverpool L3 5QA, UK

Full list of author information is available at the end of the article
}

(c) The Author(s). 2020 Open Access This article is licensed under a Creative Commons Attribution 4.0 International License, which permits use, sharing, adaptation, distribution and reproduction in any medium or format, as long as you give appropriate credit to the original author(s) and the source, provide a link to the Creative Commons licence, and indicate if changes were made. The images or other third party material in this article are included in the article's Creative Commons licence, unless indicated otherwise in a credit line to the material. If material is not included in the article's Creative Commons licence and your intended use is not permitted by statutory regulation or exceeds the permitted use, you will need to obtain permission directly from the copyright holder. To view a copy of this licence, visit http://creativecommons.org/licenses/by/4.0/. The Creative Commons Public Domain Dedication waiver (http://creativecommons.org/publicdomain/zero/1.0/) applies to the data made available in this article, unless otherwise stated in a credit line to the data. 
(Continued from previous page)

Systematic review registration number: PROSPERO CRD42018079526.

Keywords: Maternal morbidity, Multimorbidity, Pregnancy and childbirth, Burden of disease, Measurement, Data collection, Low- and middle-income countries

\section{Background}

Maternal multimorbidities affect millions of women during pregnancy and after childbirth and the burden of illhealth is expected to be highest in women in low-and middle-income countries (LMIC) [1]. For every maternal death, 20 to 30 women have morbidities related to pregnancy or childbirth $[2,3]$. More recent studies using new and comprehensive assessment tools suggest that the magnitude of maternal multimorbidity is much larger than previously estimated [4-6]. International targets and the Sustainable Development Goals have a new focus; in addition to preventing maternal mortality, improving health and well-being, as well as "survive and thrive" are the new goals [7]. There is international agreement that all women have the right to the highest attainable standard of health and well-being, also during pregnancy and after childbirth [7, 8]. Estimates of morbidity have until now largely focused on acute and/or severe complications such as haemorrhage, sepsis and eclampsia [9]. The current definition of health is "a state of complete physical, mental, and social well-being and not merely the absence of disease or infirmity" [10]. There are arguments that this definition needs to be re-formulated to consider health in a context of functionality, capacity, adaptability and the ability to perform activities of daily living despite having an illness or disability; but with a continued emphasis on the importance of the three domains of health: physical, psychological and social [11]. There is also debate that current definitions, measurements and timeframes for "multimorbidity", "co-morbidity", "morbidity burden" and related constructs are not well conceptualized $[11,12]$.

Regarding maternal morbidity, a suggested definition is "any health condition attributed to and/or aggravated by pregnancy and childbirth that has a negative impact on women's well-being" [13]. In order to address all health needs that women may have when attending for maternity care, it is important to be able to identify all types of morbidities and understand how each morbidity influences other aspects of women's health and wellbeing during pregnancy and after childbirth. To date, lack of data exist regarding measurement and burden of disease described as "maternal morbidity", "maternal multimorbidity", or "maternal co-morbidity"; these terms are often used interchangeably; and there is uncertainty regarding the timeframe over which maternal morbidity impacts a woman's health and wellbeing. Additionally, there is limited understanding of best practices to measure different components of maternal ill-health and descriptions of morbidities, and if and how different types of morbidities are interlinked and associated.

\section{Objective}

A systematic review of the literature was conducted for studies from LMIC that measured two or more different types of maternal morbidity and/or associations with and between morbidities.

\section{Methods}

We included studies which assessed two or more types of maternal morbidity in women during and/or after pregnancy. For the purposes of this study we categorised maternal multimorbidity as physical (such as but not limited to medical, infectious, obstetric), psychological (such as but not limited to depression, suicidal ideation) and social co-morbidities (such as but not limited to domestic violence, substance misuse) [5]. We assessed tools that were used to collect data, including self-reported subjective measures; and/or objective measures such as clinical examination; and/or use of investigations for different types of maternal multimorbidity as reported by authors. We described how and what different types of maternal multimorbidity (physical, psychological, social) were measured and if there were any reported associations between these.

\section{Data sources and search strategy}

This protocol is registered in PROSPERO (CRD42018079526). Relevant articles published between January 2007 and December 2018 were identified using a structured search strategy in four electronic databases: CINAHL Plus, Global Health, Medline, and Web of Science. A search strategy was developed using thesaurus (including $\mathrm{MeSH}$ ) and free-text terms for "maternal morbidity" and associated keywords, were used as main search terms. For each aspect of maternal morbidity ("physical", "psychological" and "social") search terms and related keywords were selected (Supplementary Table 1). Reference lists and bibliographies of key topic articles were also searched and any additional papers that met the inclusion criteria were obtained.

\section{Inclusion and exclusion criteria}

The study population was limited to women during pregnancy, childbirth or up to 12 weeks postnatal. Studies were excluded if: (i) they reported one type of 
maternal morbidity only, (ii) examined trend, risk factors or associations only without estimates of prevalence of types of morbidity, or (iii) reported severe or lifethreatening complications of pregnancy or childbirth that would require emergency obstetric care. The review was limited to studies from LMIC as defined by the World Bank. Language was limited to English.

\section{Selection and data extraction}

One researcher screened all titles and abstracts (MMc). A sub-sample (20\%) was double screened by the second researcher (SZ). Evaluation of full-text papers was done independently by these two researchers with reasons for exclusion recorded and any discrepancies were discussed with a third researcher (NvdB). Information was extracted into a pre-designed summary table and included data on location of study, study dates, study design, study population, types of maternal morbidity, methods of measurement, timing (pregnancy phase) of the assessment and whether or not associations were reported (Supplementary Table 2). Throughout the review and extraction process, articles where uncertainty existed were discussed by all researchers to reach consensus.

\section{Quality assessment}

Appraisal of the quality of studies was conducted based on descriptions of maternal morbidities, sampling methods and completeness of data. Quality of evidence for each study was assessed using the Grading of Recommendations, Assessment Development and Evaluation (GRADE) tool adapted from the Critical Analysis Skills Programme (CASP) tool [14].

\section{Data synthesis}

A narrative synthesis approach was used to describe outcomes including: types of maternal morbidity categorised as physical (such as medical, infectious, obstetric), psychological (such as depression, suicidal ideation) and social (such as domestic violence, substance misuse); approaches used to collect data (self-reported or determined by healthcare providers); data collection tools used (standardised validated tool, or study specific); measurements of maternal morbidities; and reported associations (if any) between different types of maternal morbidities.

\section{Results}

By combining the search terms, 2840 studies were identified from the four databases and after screening for relevance, 58 were retrieved for full text review (Fig. 1). Upon applying the eligibility criteria, 38 articles met the inclusion criteria. Two studies were conducted by the same group of authors [15-18]. In these publications, the same methodology was reported in two papers, but there was a different emphasis on the results and outcomes reported per publication. For the purposes of this review, the first publication is referenced in the methodology section [15, 17]. Both publications were included in the summary tables and measurements and/or associations for each publication are described in the results section. Most studies $(92 \%$; 33/36) were of medium quality, and the rest low quality $(8 \%, 3 / 36)$.

\section{Characteristics of studies}

The 36 studies were from 17 different countries, with 15 from sub-Saharan Africa. Eleven were conducted in lowincome countries and six in middle-income countries (four lower-middle and two upper-middle income countries).

\section{Study design, source of data, data collection method and sample size}

Twenty-six studies used cross-sectional survey study designs. Four were observational prospective cohort studies $[15,19-21]$. One study was a case control [22]. Twenty five studies used face-to-face interviews or consultations to collect self-reported primary data from women using questionnaires. Most studies that collected primary data relied on women's self-reported symptoms $(n=28)$. In four studies, clinical examination and/or laboratory tests were also conducted $[6,20,23,24]$. Three studies extracted data using secondary data analysis of large databases of hospital admissions, discharges or birth registers [25-27]. In these secondary data analyses authors used their own data collection tools with little details of the variables extracted. One study extracted data from medical case notes [28] (Supplementary Table 2). A total number of 71,229 women were assessed in the 36 studies: 60,911 during pregnancy and 10,318 after childbirth. In nine studies less than 500 women were assessed [24-33]; thirteen assessed 500-999 women each $[15,18,20,21,34-43]$. In nine studies 1000-1999 women were assessed $[19,22,27,28,44-48]$; and five had sample sizes of $\geq 2000$ women (Supplementary Table 2) $[6,25,26,49,50]$.

\section{Stages of pregnancy assessed}

A total of 23 studies collected data from women during pregnancy: in the second trimester [16, 19, 32, 40, 47]; in the third trimester [20,24,37]; or at any time during pregnancy $[19,29,32,33]$. In 11 of those, gestational age was not given [32, 36, 38-45, 48, 49]. Seven studies assessed women within 12 weeks of childbirth $[18,22$, $29,30,32,46,50]$. In one study, data was collected during three stages after childbirth: at 4-12 weeks; at 12-24 weeks; and at 24-56 weeks [23]. Zafar et al. collected data at three different assessment stages, during early 


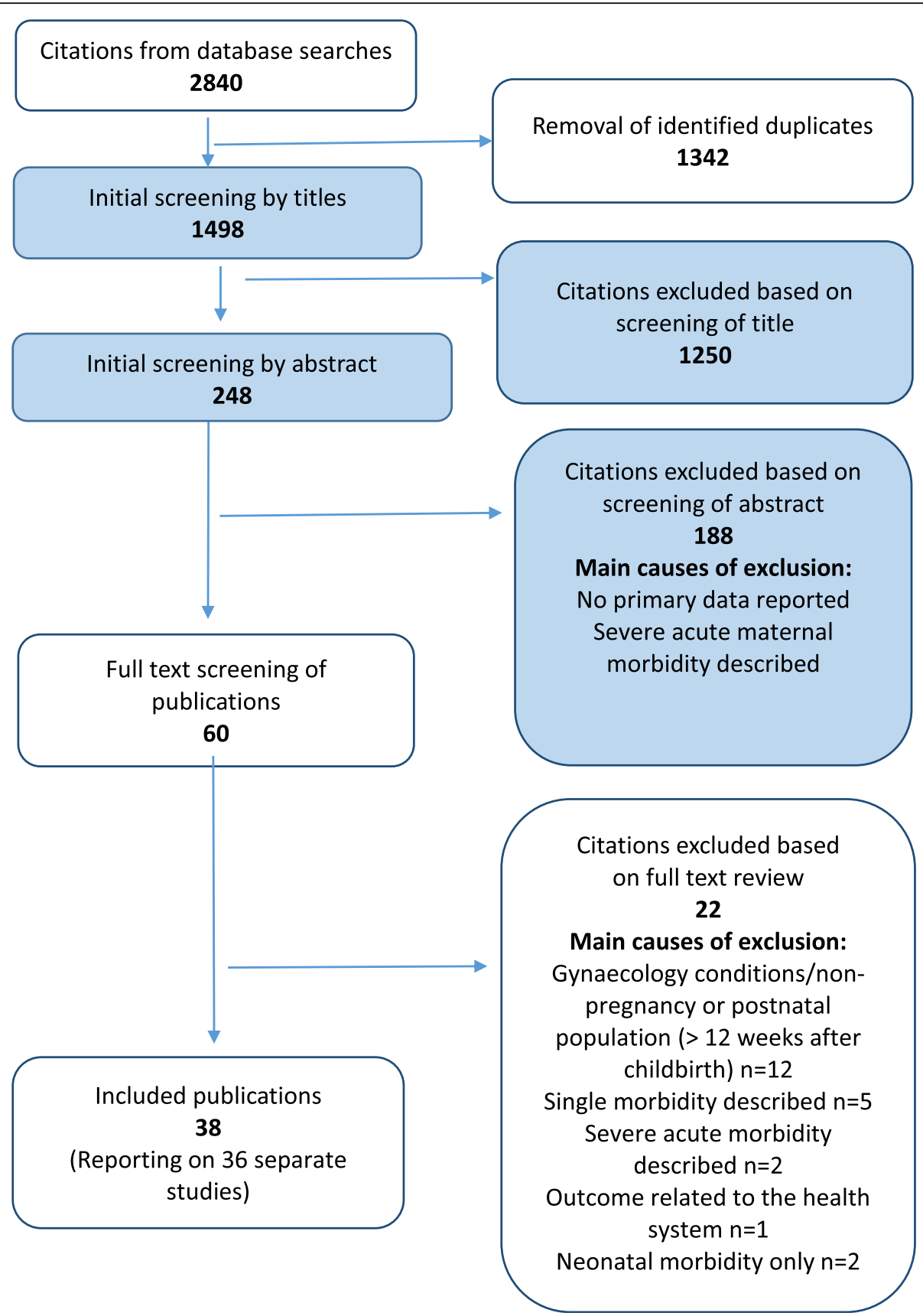

Fig. 1 PRISMA diagram for article selection process

and late antenatal period and after childbirth (Supplementary Table 2) [6].

\section{Site of data collection}

In studies that collected primary data $(n=30)$, data collection took place during visits for routine antenatal or postnatal care in outpatient departments of healthcare facilities: tertiary/provincial hospitals $[23,31,35,38,41$, $44,46]$; secondary level or district hospitals [32, 43, 51], and primary healthcare facility level $[15,18,36,39,47]$.
For four studies the site was unclear [29, 33, 34, 42]. In 12 studies, this took place in the community or in women's homes (Supplementary Table 2) $[6,19,20,22$, $24,30,42,45,49-51]$.

\section{Maternal multimorbidity}

All three types of maternal morbidity including physical, psychological and social ill-health were assessed in 12 studies $[6,15,16,20,39,41-43,46,48]$; psychological and social ill-health were assessed in nine studies [18, 
$25,29,31,32,34,35,39,42]$; physical and psychological ill-health in 11 [6, 18, 19, 21, 22, 24, 27, 29, 32, 33, 49]; and physical and social ill-health in six $[17,26,44,45$, 47, 50] (Supplementary Table 2).

\section{Physical morbidity}

Twenty-nine studies reported on different types of physical morbidity; three of which assessed pre-selected populations including women with HIV $[35,42]$ or women with gestational diabetes [38]. A variety of data collection tools were used, but generally not well described. No study used validated questionnaires or international disease classifications. The most commonly reported physical morbidities were anaemia in six studies (prevalence range 5.0-57.7\%) [6, 20, 22, 23, 32, 49], and HIV in nine (prevalence range $3.0-16.0 \%)[6,16,29,33,35$, $36,43,48,50]$. There was a variety of other types of physical morbidities, with wide ranges for some conditions such as antepartum haemorrhage; nausea and vomiting; preterm birth; malaria; reproductive or sexually transmitted infection; urinary tract infection (Supplementary Table 3). Some authors used summative aggregated measures, for example "gynaecological and obstetric problems" as occurring in $10-22 \%$ of women; "multiple morbidities" in $60 \%$ of women or "at least one reported symptom" (44\% occurrence) [22, 46, 49]. One study used antenatal hospitalisation as a "proxy" for physical morbidities (55.4\% of women) [45] (Supplementary Table 3).

\section{Psychological morbidity}

Of the 32 studies that report psychological morbidities, the most common condition was depression with a prevalence range of $13.5-39.5 \%$ across 21 studies [18, 20-24, 27-35, 38, 41, 49, 51]. Twelve studies described more than one psychological condition $[15,16,19,25$, $34,37,42,43,46-49]$. Some authors described aggregates or a summative psychological condition; for example, "common mental disorders" and "symptoms of any mental distress" $[15,16]$. There was a range of other types of psychological morbidity described, such as anxiety; suicidal ideation; and distress (Supplementary Table 4). Fourteen different data collection tools were used either alone or in combination (Table 1). The commonest tool was the Edinburgh Postnatal Depression Score (EPDS) questionnaire, used in fourteen studies [6,

Table 1 Description of data collection tools used to assess psychological and social morbidity

\begin{tabular}{|c|c|c|c|}
\hline No. & Data collection tools to assess psychological morbidity & $\begin{array}{l}\text { International } \\
\text { abbreviation }\end{array}$ & Original country, author, and date \\
\hline 1. & Aga Khan University Anxiety and Depression Scale & AKUADS & Pakistan, Ali 1988 [52] \\
\hline 2. & Clinical Interview Schedule-Revised & CIS-R & USA, Lewis 1992 [53] \\
\hline 3. & Edinburgh Postnatal Depression Scale & EPDS & UK, Cox 1987 [54] \\
\hline 4. & Harvard Trauma Questionnaire & HTQ & USA, Mollica 1992 [55] \\
\hline 5. & Kessler-10 item psychological distress scale & $\mathrm{K}-10$ & USA, Kessler 2002 [56] \\
\hline 6. & List of Threatening Experiences questionnaire & LTE-Q & UK, Brugha 1985 [57] \\
\hline 7. & Montgomery-Åsberg Depression Rating scale & MADRA & UK, Montgomery 1979 [58] \\
\hline 8. & Patient Health Questionnaire & PHQ-9 & USA, Spitzer 1992 [59] \\
\hline 9. & Self-Reporting Questionnaire-(20 Items) & SRQ-20 & $\begin{array}{l}\text { WHO, Switzerland, Beusenberg } 1994 \\
\text { [60] }\end{array}$ \\
\hline 10. & State-Trait Anxiety Inventory & STAI & USA, Spielberger 1983 [61] \\
\hline 11. & $\begin{array}{l}\text { Structured Clinical Interview for the Diagnostic and Statistical Manual of Mental } \\
\text { Disorders, 4th Edition }\end{array}$ & SCI- DSM IV & $\begin{array}{l}\text { USA, American Psychiatric } \\
\text { Association } 1994 \text { [62] }\end{array}$ \\
\hline 12. & WHO version of the Centre for Epidemiological Studies Depression scale & CES-DR & USA, Radloff 1977 [63] \\
\hline 13. & Mini-intentional neuropsychological & MINI & USA, Sheehan, 1998 [64] \\
\hline No. & Data collection tools to assess social morbidity & $\begin{array}{l}\text { International } \\
\text { abbreviation }\end{array}$ & Original country, author, and date \\
\hline 1. & Alcohol Use Disorders Identification Test & AUDIT & WHO, Babor 2001 [65] \\
\hline 2. & CAGE (Cut-annoyed-guilty-eye) Questionnaire & CAGE & USA, Ewing 1970 [66] \\
\hline 3. & Maternity Social Support Index & MSSI & USA, Pascoe 1988 [67] \\
\hline 4. & Social Provisions Scale & SPS & USA, Cutrona 1987 [68] \\
\hline 5. & HIV-AIDS Stigma Instrumental PHWHA & HASI-P & WHO, Babor 2001 [69] \\
\hline
\end{tabular}


18, 20, 28-31, 34-36, 38, 41, 49]. However, different studies used various cut-off scores (from $\geq 4$ to $\geq 13$ ) for the EPDS questionnaire and the Kessler scale (from $>15$ to $>30)[6,18,20,28-31,34-36,38,41,49,54,56]$.

\section{Social morbidity}

In total, 27 studies assessed social morbidity; the most commonly reported type of social morbidity was domestic violence in 14 studies [17, 18, 23, 25, 28, 31, 35, 38, $39,43,45,47,48,50]$. Substance abuse was assessed in nine studies (Supplementary Table 4) [16, 34, 39, 40, 42, 44-46, 50]. Three studies assessed both domestic violence and substance abuse [26, 37, 46]. Eight studies assessed other aspects of social health including husband's alcohol intake, poor social support, food insecurity and unplanned pregnancy $[20,21,30,36,41,42,46$, 51].

In the 14 studies assessing domestic violence, a variety of data collection tools were used and most authors used their own definitions and questionnaires to screen for domestic violence. Five publications used all or part of internationally recognised questionnaires (Table 1) [17, 18, 39, 45, 47]. Different types of domestic violence included: disrespect, forced sex, intimate partner violence, physical assault, severe emotional and verbal abuse. Other authors used descriptions of domestic violence as aggregates or summative measures, for example, terms such as "multiple acts of physical violence" and "physical and/or sexual abuse" [38]. Nine studies assessed one or more forms of substance abuse [16, 34, 39, 40, 42, 44$46,50]$, and two of these used validated questionnaires $[34,40]$. In general, substance abuse related to alcohol (9 studies; prevalence range 0-49.5\%) [16, 34, 39-41, 44$46,50]$.

\section{Associations between different types of morbidity}

For physical morbidity, there was an association between increased psychological morbidity in women with obstetric complications (haemorrhage, infections, incontinence, prolonged labour, caesarean birth, low birthweight, stillbirth, neonatal death) (Table 2) [6, 26, 41, 45, 50]. Women with gestational diabetes were not more likely to have psychological morbidity (depression) [38], but women with HIV were more likely to have social morbidity (domestic violence) [18]. Psychological morbidity was more common in younger women [40] and among women with social morbidities such as domestic violence [25, 35], unwanted pregnancy [19, 41, 50] and poor social support (Table 2) [41]. For social morbidity, there was an association between women with substance abuse (alcohol) and domestic violence [48]' and domestic violence was also associated with neonatal death [48] and maternal complications (Table 2) [46]. Due to heterogeneity, meta-analysis of associations was not possible.

\section{Discussion}

\section{Main findings}

There is emerging evidence of a high burden of multimorbidity in women living in LMIC during pregnancy and after childbirth, as well as emerging evidence of associations between physical, psychological and social morbidities, suggesting that maternal morbidities are inter-linked. There is, however, still limited data about the strengths and direction of the associations between the different types of morbidities.

There was an apparent lack of standardisation of definitions and data collection tools used to measure maternal multimorbidities. The EPDS was the most common validated data collection tool to assess psychological morbidity in the studies, but with different cut-off scores to determine the risk of "depression" (ranging from 4 to 13) making comparisons difficult. Similarly, a variety of different validated data collection tools were used to assess domestic violence and/or substance abuse as components of social morbidity. Physical, psychological and social morbidities were often described as aggregates or summative measures, limiting comparability of findings.

\section{Strengths and limitations}

To the best of our knowledge, this is the first systematic review to assess maternal multimorbidities and types and levels of association between the different types. Many studies relied on recall of experience of morbidity and many primary data were symptom-based rather than "diagnosed". Only four studies triangulated self-reported symptoms with findings from clinical examination and/ or basic laboratory investigations. Assessments of measurements of ill-health based on self-reporting may be valid regarding ill-health as experienced by women, but do not provide accurate burden of disease estimates. No study described or used internationally recognised disease classifications to assess physical morbidity. Internationally recognised data collection tools were used to assess psychological and social morbidity, but these often used different cut-off scores making comparisons difficult. A limitation of this review is that studies that explored maternal multimorbidity using qualitative methodology were excluded.

\section{Interpretation}

Valid comparable measurements of maternal multimorbidity are limited to date, and this study confirms the need for a new approach and focus [70-72]. It will be important for future healthcare practice and research to agree and apply: (a) common identification criteria for maternal multimorbidity taking into account the different types of physical, psychological and social morbidity; (b) standardised and validated data collection tools that can be used in different languages and at all levels of healthcare; with, 
Table 2 Associations between types of maternal morbidity

\begin{tabular}{|c|c|c|}
\hline $\begin{array}{l}\text { Type of } \\
\text { morbidity }\end{array}$ & Author, date & Associations between different types of maternal morbidity \\
\hline \multirow[t]{3}{*}{$\begin{array}{l}\text { Physical } \\
\text { morbidity }\end{array}$} & $\begin{array}{l}\text { Shamu } \\
2014[18]\end{array}$ & $\begin{array}{l}\text { Positive HIV status was associated with intimate partner violence for pregnant women: partially adjusted OR } \\
\text { 1.43: (95\%Cl: } 1.00-2.05) \text {. }\end{array}$ \\
\hline & $\begin{array}{l}\text { Surkan } \\
2017[26]\end{array}$ & 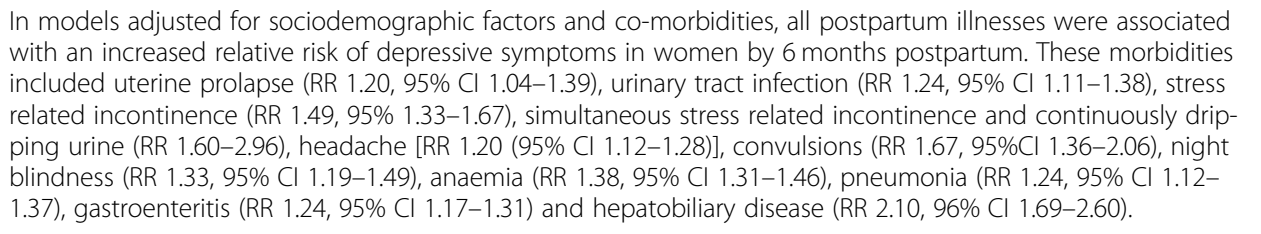 \\
\hline & $\begin{array}{l}\text { Zafar } \\
2015[6]\end{array}$ & $\begin{array}{l}\text { Multivariate logistic regression showed that for pregnant women in Malawi, after controlling for parity and } \\
\text { pregnancy stage, antepartum bleeding increased the odds of psychological morbidity } 5 \text {-fold (OR: } 5.01 ; 95 \% \mathrm{Cl} \\
1.60,15.70 ; p=0.006) \text {. Infective morbidity (i.e. for each additional infective morbidity) showed more than } 2.5- \\
\text { fold increase in the odds of having psychological morbidity (OR: } 2.58 ; 95 \% \mathrm{Cl} 1.92,3.47 ; p=0.000) \text {. For Pakistan, } \\
\text { there was a } 56 \% \text { increase in odds of psychological morbidity due to increasing burden of infective morbidity } \\
\text { (OR: } 1.56 ; 95 \% \mathrm{Cl} 1.36,1.79 ; p=0.000) \text {, and } 78 \% \text { increased odds due to increasing burden of non-infective mor- } \\
\text { bidity (OR: } 1.78 ; 95 \% \mathrm{Cl} 1.51,2.11 ; p=0.000) \text {, when controlling for the effect of complications during previous } \\
\text { pregnancy. Complications during previous pregnancy, infective morbidity }(p<0.001) \text {, intra or postpartum } \\
\text { haemorrhage }(p<0.02) \text { were associated with psychological morbidity in both settings. }\end{array}$ \\
\hline
\end{tabular}

\section{Psychological morbidity}

Faisal-Cury 2009 [16]

Faisal-Cury 2010 [15]

Karmaliana 2009 [19]

Hanlon 2009

Nasreen 2011

[37]

Natasha 2015

[38]

Prost

2012 [50]

Rees $2016[47]$

Ukacukw 2009 [28]

Waqas 2015 [41]

Wong 2017 [42]

Social morbidity Hassan 2014 [44]

RomeroGutiérrez 2011 [46]

Stöckl 2010 [48]
Obstetric complications were independently associated with common mental disorders in pregnant women.

Common mental disorders during pregnancy were not associated with risk of preterm birth (adjusted OR: 1.03, 95\% Cl: 0.57-1.88) or low birth weight (adjusted OR: 1.09, 95\% Cl: 0.62-1.91).

Psychological distress in pregnant women was associated with husband unemployment $(p=0.032)$, lower household wealth $(p=0.027)$, having 10 or more years of formal education $(p=0.002)$, first $(p=0.002)$ and unwanted pregnancies $(p<0.001)$.

Significant associations exist between pregnant women who report intimate partner violence and preterm labour, need for caesarean section, antenatal hospitalization and vaginal bleeding.

Increasing levels of common mental disorder symptoms in pregnant women were associated with prolonged labour (> 24 h) (SRQ 1-5: RR 1.4; 95\% Cl 1.0-1.9, SRQ > or =6: RR 1.6; 95\% Cl 1.0-2.6).

There was no association between women with depression and gestational diabetes mellitus or other obstetric factors. However, pregnant women's level of literacy, poor household economy, poor relationship with husbands, and partner violence showed strong associations with depression and anxiety.

Unwanted pregnancy, small perceived infant size and stillbirth or neonatal deaths were all independently associated with increased risk of psychological distress in postnatal women. Loss of infants or unwanted pregnancies increased the risk of distress considerably (aORs: 7.06 95\% Cl: 5.51-9.04 and 1.49, 95\% Cl: 1.121.97).

For pregnant women with any mental distress, adjusted odds ratios for four or more traumatic events and severe psychological abuse was 3.60 (95\% Cl 2.08-6.23); for four or more traumatic events and physical abuse 7.03 (95\% Cl 3.23-15.29); and for four or more traumatic events and severe psychological and physical abuse the adjusted OR was 10.45 (95\% Cl 6.06-18.01). For pregnant women who reported four or more traumatic events, and either physical abuse alone or in combination with severe psychological abuse, there was a 10 -fold increase in depressive and other mental health symptoms.

After multivariable adjustment, intimate partner violence intensity had a strong and statistically significant association with depression symptom severity for pregnant women.

Results of unadjusted log-binomial regression showed that unwanted pregnancy, prenatal depression and social support were associated with low birth weight.

Inferential analysis revealed that higher HADS scores were significantly associated with lower social support scores, rural background, history of harassment, abortion, caesarean birth and unplanned pregnancies $(P<.05)$.

A significant association was found between pregnant women reporting intimate partner violence and preterm labour [adjusted odds ratio (adjOR) 1.54, 95\% confidence interval (CI) 1.16-2.03], caesarean section (adjOR 11.84, 95\% Cl 6.37-22.02), antenatal hospitalization (adjOR 6.34, 95\% Cl 3.82-10.52) and vaginal bleeding (adjOR 1.51, 95\% Cl 0.9-2.3).

Maternal complications were higher in pregnant women who experienced violence $(30.2 \%$ vs $23.6 \%, p=$ 0.004). Pregnant women who experienced sexual violence had more maternal complications (43.2\%), and pregnant women who experienced psychological violence had more neonatal complications (54.2\%).

Women's odds of drinking alcohol during pregnancy were significantly increased if they had experienced violence during pregnancy. Violence during pregnancy was also associated with having had a child or infant that died. 
(c) validation of self-reported measurements of maternal morbidity compared to clinical assessment, investigations and diagnosis determined by healthcare providers $[6,70-$ 72]. More recognition must be given that maternal morbidity is a complex concept with important associations between different morbidities. This has implications for screening and management of all different types of illhealth during pregnancy and after childbirth. There is a need to incorporate women's understanding, perceptions and lived experience of maternal multimorbidity into public health approaches to improve maternal health and wellbeing during pregnancy and after childbirth in LMIC $[73,74]$

\section{Conclusion}

To date a range of methods and tools have been used to assess maternal multimorbidity. Maternal multimorbidity estimates using these methodologies and tools, while useful as a guide, cannot be considered truly representative of the burden and range of maternal multimorbidity that have negative impact on women's wellbeing during pregnancy and after childbirth. The suggested WHO definition of maternal morbidity provides such a framework in principle, but challenges remain to map out comprehensive, feasible and acceptable assessment tools, approaches and timeframes [11]. Comprehensive and routine measurements of maternal multimorbidity are necessary to inform policy and program decisions and for resource allocation for antenatal and postnatal care [5]. Improved standardised measurements of maternal multimorbidity will also allow for comparison of the burden of disease across settings within and between countries. There is a need for a sustainable way to provide good baseline maternity care for all and targeted individualised care for women who need extra care to prevent development and progression of maternal multimorbidity.

\section{Supplementary information}

Supplementary information accompanies this paper at https://doi.org/10. 1186/s12884-020-03303-1.

Additional file 1: Supplementary Table 1. MeSH terms and keywords used in the search.

Additional file 2: Supplementary Table 2. Summary table for studies reporting maternal multimorbidity during pregnancy and after childbirth and /or associations between the multimorbidities.

Additional file 3: Supplementary Table 3. Summary table of types of physical morbidity reported in included studies.

Additional file 4: Supplementary Table 4. Summary table of measurements of psychological and social morbidities reported.

\section{Abbreviations}

EPDS: Edinburgh Postnatal Depression Score; CASP: Critical Analysis Skills Programme; GRADE: Grading of Recommendations, Assessment, Development and Evaluation; LMIC: Low- and middle-income countries; MeSH: Medical Subject Headings; PRISMA: Preferred Reporting Items for Systematic Reviews and Meta-Analyses; WHO: World Health Organization

\section{Acknowledgements}

Not applicable.

\section{Authors' contributions}

$M M c$ and $\mathrm{NvdB}$ were responsible for the study inception and design. MMc and SZ performed the data extraction. MMc and NvdB interpreted the data and wrote the manuscript. All authors have read, critiqued and approved the final manuscript.

\section{Funding}

This study was funded by a grant from the Department of International Development, London UK, under the Making it Happen programme (202945-101) and Global Fund (20168770) and the EGA Hospital Charity Travelling Fellowship in Memory of Anne Boutwood from the Royal College of Obstetricians and Gynaecologists. The funders played no role in the writing of the manuscript or the decision to submit it for publication.

Availability of data and materials

All the sources of data are publicly available and referenced in the document.

\section{Ethics approval and consent to participate}

This systematic review did not involve contact with any human participants, and therefore no ethical approval was needed. This study was conducted in compliance with the established ethical guidelines of the Declaration of Helsinki.

\section{Consent for publication}

Not applicable.

\section{Competing interests}

The authors have no competing interests to declare.

\section{Author details}

${ }^{1}$ Centre for Maternal and Newborn Health, Liverpool School of Tropical Medicine, Pembroke Place, Liverpool L3 5QA, UK. ${ }^{2}$ Fazaia Medical College, Air University, Islamabad, Pakistan.

Received: 23 February 2020 Accepted: 30 September 2020

Published online: 20 October 2020

\section{References}

1. Graham W, Woodd S, Byass P, Fillipi V, Gon G, Virgo S, et al. Diversity and divergence: the dynamic burden of poor maternal health. Lancet. 2016; 388(10056):2164-75. https://doi.org/10.1016/S0140-6736(16)31533-1.

2. Ashford L. Hidden suffering: disabilities from pregnancy and childbirth in less developed countries. Washington, DC: Population Reference Bureau, MEASURE Communication; 2002.

3. Datta KK, Sharma RS, Razack PMA, Ghosh TK, Arora RR. Morbidity pattern among rural women in Alwar-Rajasthan - a cohort study. Health Popul Perspect Issues. 1980;3(4):282-92

4. Barreix M, Barbour K, McCaw-Binns A, Chou D, Petzold M, Gichuhi G, et al. Standardizing the measurement of maternal morbidity: pilot study results. Int J Gynecol Obstet. 2018;141(Supp 1):10-9. https://doi.org/10.1002/ijgo. 12464.

5. McCauley M, Madaj B, White SA, Dickinson F, Bar-Zeev S, Aminu M, et al. Burden of physical, psychological and social ill-health during and after pregnancy among women in India, Pakistan, Kenya and Malawi. BMJ Glob Health. 2018:3(3):e000625. https://doi.org/10.1136/bmigh-2017-000625.

6. Zafar S, Jean-Baptiste R, Rahman A, Neilson JP, van den Broek NR. Non-life threatening maternal morbidity: cross sectional surveys from Malawi and Pakistan. PLoS One. 2015;10(9):e0138026.

7. United Nations. Transforming our world: the 2030 Agenda for Sustainable Development. New York: World Health Organization; 2015. Accessed 17th November 2017. Available from: https://sustainabledevelopment.un.org/ post2015/transformingourworld.

8. United Nations. Every Woman, Every Child: Global Strategy; 2015. Accessed 17th November 2017. Available from: http://www.everywomaneverychild. org/global-strategy-2.

9. Vos T, Barber RM, Bell B, et al. Global, regional, and national incidence, prevalence, and years lived with disability for 301 acute and chronic 
diseases and injuries in 188 countries, 1990-2013: a systematic analysis for the Global Burden of Disease Study 2013. Lancet. 2015;386:743-800. https:// doi.org/10.1016/S0140-6736(15)60692-4.

10. World Health Organization. Constitution of the World Health Organization. Geneva: World Health Organization; 1948.

11. Huber M, Knottnerus JA, Green L, et al. How should we define health? BMJ. 2011;343:d416

12. Valderas JM, Starfield B, Sibbald B, Salisbury C, Roland M. Defining comorbidity: implications for understanding health and health services. Ann Fam Med. 2009;7(4):357-63. https://doi.org/10.1370/afm.983.

13. Firoz T, Chou D, von Dadelszen P, Agrawal P, Vanderkruik R, Tunçalp Ö, et al. Measuring maternal health: focus on maternal morbidity. Bull World Health Organ. 2013;91(10):794-6.

14. Atkins D, Eccles M, Flottorp S, Guyatt GH, Henry D, Hill S, et al. Systems for grading the quality of evidence and the strength of recommendations I: critical appraisal of existing approaches. The GRADE Working Group. BMC Health Serv Res. 2004;4(1):38.

15. Faisal-Cury A, Araya R, Marcelo Z, Menezes P. Common mental disorders during pregnancy and adverse obstetric outcomes. J Psychosom Obstet Gynecol. 2010;31(4):229-35

16. Faisal-Cury A, Menezes P, Araya R, Zugaib M. Common mental disorders during pregnancy: prevalence and associated factors among low-income women in São Paulo, Brazil. Arch Womens Ment Health. 2009;12(5):335.

17. Shamu S, Zarowsky C, Roelens K, Temmerman M, Abrahams K. Highfrequency intimate partner violence during pregnancy, postnatal depression and suicidal tendencies in Harare, Zimbabwe. Gen Hosp Psychiatry. 2016; 38(Jan-Feb):109-14.

18. Shamu S, Zarowsky C, Shefer T, Temmerman M, Abrahams N. Intimate partner violence after disclosure of HIV test results among pregnant women in Harare, Zimbabwe. PLoS One. 2014;9(10):e109447.

19. Karmaliani R, Asad N, Bann CM, Moss N, McClure EM, Pasha O, et al. Prevalence of anxiety, depression and associated factors among pregnant women of Hyderabad. Pakistan Int J Soc Psychiatry. 2009;55(5):10.

20. Tran TD, Biggs B-A, Tran T, Casey GJ, Hanieh S, Simpson JA, et al. Psychological and social factors associated with late pregnancy iron deficiency anaemia in rural Viet Nam: A population-based prospective study. PLoS One. 2013;8(10):e78162 19.

21. Wado YD, Afework MF, Hindin MJ. Effects of maternal pregnancy intention, depressive symptoms and social support on risk of low birth weight: a prospective study from southwestern Ethiopia. PLoS One. 2014;9(5):e96304.20.

22. Assarag B, Dubourg D, Maaroufi A, Dujardin B, De Brouwere V. Maternal postpartum morbidity in Marrakech: what women feel what doctors diagnose? BMC Pregnancy Childbirth. 2013;13:225.

23. Chersich MF, Kley N, Luchters SMF, Njeru C, Yard E, Othigo MJ, et al Maternal morbidity in the first year after childbirth in Mombasa Kenya; a needs assessment. BMC Pregnancy Childbirth. 2009;9:51.

24. Rahman A, Bunn J, Lovel H, Creed F. Association between antenatal depression and low birthweight in a developing country. Acta Psychiatr Scand. 2007;115(6):481-6

25. Isaksen AB, Østbye T, Mmbaga BT, Daltveit AK. Alcohol consumption among pregnant women in northern Tanzania 2000-2010: a registry-based study. BMC Pregnancy Childbirth. 2015;15:205.

26. Surkan PJ, Sakyi KS, Christian P, Mehra S, Labrique A, Ali H, et al. Risk of depressive symptoms associated with morbidity in postpartum women in rural Bangladesh. Matern Child Health J. 2017;21(10):1890-900.

27. Tsai AC, Tomlinson M, Comulada WS, Rotheram-Borus MJ. Intimate partner violence and depression symptom severity among south African women during pregnancy and postpartum: population-based prospective cohort study. PLoS Med. 2016;13(1):e1001943.

28. Ukachukwu V, Unger H, Onoka C, Nduka C, Maina S, Ngugi N. Maternal morbidity and mortality in peri-urban Kenya-assessing progress in improving maternal healthcare. East Afr J Public Health. 2009;6(2):112-8.

29. Chibanda D, Mangezi W, Tshimanga M, Woelk G, Rusakaniko S, StranixChibanda L, et al. Postnatal depression by HIV status among women in Zimbabwe. J Women's Health. 2010;19(11):2071-7.

30. Dewing S, Tomlinson M, Le Roux IM, Chopra M, Tsai AC. Food insecurity and its association with co-occurring postnatal depression, hazardous drinking, and suicidality among women in peri-urban South Africa. J Affect Disord. 2013;150(2):460-5.
31. Khalifa DS, Glavin K, Bjertness E, Lien L. Determinants of postnatal depression in Sudanese women at 3 months postpartum: a cross-sectional study. BMJ Open. 2016;6:e009443.

32. Lukose A, Ramthal A, Thomas T, Bosch R, Kurpad AV, Duggan C, et al. Nutritional factors associated with antenatal depressive symptoms in the early stage of pregnancy among urban south Indian women. Matern Child Health J. 2014;18(1):161-70.

33. Natamba BK, Achan J, Arbach A, Oyok TO, Ghosh S, Mehta S, et al. Reliability and validity of the Center for Epidemiologic Studies Depression Scale in screening for depression among HIV-infected and uninfected pregnant women attending antenatal Services in Northern Uganda: a cross-sectional study. BMC Psychiatr. 2014;14:2197.

34. Vythilingum $B$, Roos A, Faure SC, Geerts L, Stein DJ. Risk factors for substance use in pregnant women in South Africa. S Afr Med J. 2012;102(11 Pt 1):851-4.

35. Yator O, Mathai M, Vander Stoep A, Rao D, Kumar M. Risk factors for postpartum depression for women living with HIV attending the prevention of mother to child transmission clinic at Kenyatta National Hospital at Nairobi, Kenya. AIDS Care. 2016:28(7):884-9.

36. Brittain K, Mellins CA, Phillips T, Zerbe A, Abrams EJ, Myer L, et al. Social support, stigma and antenatal depression among HIV-infected pregnant women in South Africa. AIDS Behavior. 2017;21(1):274-82.

37. Nasreen HE, Kabir ZN, Forsell Y, Edhborg M. Prevalence and associated factors of depressive and anxiety symptoms during pregnancy: a population based study in rural Bangladesh. BMC Womens Health. 2011;11:22.

38. Natasha K, Hussain A, Khan AKA. Prevalence of depression among subjects with and without gestational diabetes mellitus in Bangladesh: a hospital based study. J Diabetes Metab Disord. 2015;14:64.

39. Ntaganira J, Muula AS, Masaisa F, Dusabeyezu F, Siziya S, Rudatskikira E. Intimate partner violence among pregnant women in Rwanda. BMC Womens Health. 2008:8:17

40. Tran TD, Tran T, Wynter K, Fisher J. Interactions among alcohol dependence, perinatal common mental disorders and violence in couples in rural Vietnam: a cross-sectional study using structural equation modeling. BMC Psychiatry. 2012;12:148

41. Waqas A, Raza N, Lodhi HW, Muhammad Z, Jamal M, Rehman A. Psychosocial factors of antenatal anxiety and depression in Pakistan: is social support a mediator? PLoS One. 2015;10(1):e0116510.

42. Wong M, Myer L, Zerbe A, Phillips T, Petro G, Mellins CA, et al. Depression, alcohol use, and stigma in younger versus older HIV-infected pregnant women initiating antiretroviral therapy in Cape Town, South Africa. Arch Womens Ment Health. 2017;20(1):149-59.

43. Stewart RC, Umar E, Tomenson B, Creed F. A cross-sectional study of antenatal depression and associated factors in Malawi. Arch Womens Ment Health. 2014;17(2):145-54.

44. Hassan M, Kashanian M, Hassan M, Roohi M, Yousefi H. Maternal outcomes of intimate partner violence during pregnancy: study in Iran. Public Health. 2014;128(5):410-5

45. Hanlon C, Medhin G, Alem A, Tesfaye F, Lakew Z, Worku B, et al. Impact of antenatal common mental disorders upon perinatal outcomes in Ethiopia: the P-MaMiE population-based cohort study. Tropical Med Int Health. 2009; 14:156-66.

46. Romero-Gutiérrez G, Cruz-Arvizu VH, Regalado-Cedillo CA. Ponce-Ponce de Leon AL. Prevalence of violence against pregnant women and associated maternal and neonatal complications in Leon, Mexico. Midwifery. 2011;27(5): 750-3.

47. Rees SJ, Tol W, Mohammad M, Tay AK, Tam N, dos Reis N, et al. A high-risk group of pregnant women with elevated levels of conflict-related trauma, intimate partner violence, symptoms of depression and other forms of mental distress in post-conflict Timor-Leste. Transl Psychiatry. 2016;6:e725.

48. Stöckl H, Watts C, Kilonzo Mbwambo JK. Physical violence by a partner during pregnancy in Tanzania: prevalence and risk factors. Reprod Health Matters. 2010;18(36):171-80.

49. Hamadani JD, Tofail F, Hilaly A, Mehrin F, Shiraii S, Banu S, et al. An association of postpartum maternal morbidities with children's mental, psychomotor and language development in rural Bangladesh. J Health Popul Nutr. 2012;30(2):193-204.

50. Prost A, Lakshminarayana R, Nair N, Tripathy P, Copas A, Mahapatra R, et al. Predictors of maternal psychological distress in rural India: a cross-sectional community-based study. J Affect Disord. 2012;138(3):277-86. 
51. Rwakarema M, Premji SS, Nyanza EC, Riziki P, Palacios-Derflingher L. Antenatal depression is associated with pregnancy-related anxiety, partner relations, and wealth in women in northern Tanzania: a cross-sectional study. BMC Womens Health. 2015;15:68.

52. Ali BS, Reza H, Khan MM, Jehan I. Development of an indigenous screening instrument in Pakistan: the Aga Khan University anxiety and depression scale. J Pak Med Assoc. 1998;48(9):261-5.

53. Lewis G, Pelosi AJ, Araya R, Dunn G. Measuring psychiatric disorder in the community: a standardized assessment for use by lay interviewers. Psychol Med. 1992;22(2):465-86.

54. Cox JL, Holden JM, Sagovsky R. Detection of postnatal depression. Development of the 10-item Edinburgh postnatal depression scale. Brit J Psychiatry. 1987;150(6):782-6.

55. Mollica RF, Caspi-Yavin Y, Bollini P, Truong T, Tor S, Lavelle J. The Harvard Trauma Questionnaire. Validating a cross-cultural instrument for measuring torture, trauma, and posttraumatic stress disorder in Indochinese refugees. J Nerv Ment Dis. 1992;180(2):111-6.

56. Kessler RC, Andrews G, Colpe L, Hiripi E, Mroczek DK, Normand SL, et al. Short screening scales to monitor population prevalence and trends in nonspecific psychological distress. Psychol Med. 2002;32(6):959-76.

57. Brugha T, Bebbington P, Tennant C, Hurry J. The list of threatening experiences: a subset of 12 life event categories with considerable longterm contextual threat. Psychol Med. 1985;15(1):189-94.

58. Montgomery SA, Asberg M. A new depression scale designed to be sensitive to change. Brit J Psychiatry. 1979;134:382-9.

59. Spitzer RL, Williams JBW, Gibbon M, First MB. The structured clinical interview for DSM-III-R (SCID). Arch Gen Psychiatry. 1992;49:624-9.

60. Beusenberg M, Orley JH. A User's guide to the self-reporting questionnaire Geneva: World Health Organization, Division of Mental Health;1994. Available from: http://www.who.int/iris/handle/10665/61113.

61. Spielberger CD. State-trait anxiety inventory STAI. Palo Alto: Consulting Psychologists Press; 1983.

62. American Psychiatric Association. Diagnostic and Statistical Manual of Mental Disorders 4. Washington, DC: American Psychiatric Association; 1994.

63. Radloff LS. The CES-D scale: a self-report depression scale for research in the general population. Appl Psychol Meas. 1977;1(3):385-401.

64. Sheehan DV, Lecrubier Y, Sheehan KH, Anorm P, Janavs J, Weiller E, et al. The Mini-international neuropsychiatric interview (M.I.N.I.): the development and validation of a structured diagnostic psychiatric interview for DSM-IV and ICD-10. J Clin Psychiatry. 1998;59(Supp 20):22-57.

65. Babor TF, Biddle-Higgins JC, Saunders JB, Monteiro MG. AUDIT: the alcohol use disorders identification test: guidelines for use in primary health care. Geneva: World Health Organization; 2001.

66. Ewing J, Rouse BA. Identifying the hidden alcoholic. Paper presented at: the 29th International Congress on Alcohol and Drug Dependence, 1970; Sydney Australia; 1970.

67. Pascoe JM, lalongo NS, Horn WF, Reinhart MA, Perradatto D. The reliability and validity of the maternal social support index. Fam Med. 1988;20(4):271-6.

68. Cutrona CE, Russell DW. The provisions of social relationships and adaptation to stress In: Jones WH, Perlman D. Advances in Personal Relationships. Greenwich: JAI Press;1987. pp. 37-67.

69. Holzemer WL, Uys LR, Chirwa ML, Greeff M, Makoae LN, Kohi TW. Validation of the HIV/AIDS stigma instrument - PLWA (HASI-P). AIDS Care. 2007;19(8): 1002-12.

70. Chou D, Tunçalp Ö, Firoz T, Barreix M, Filippi V, von Dadelszen P, et al. Constructing maternal morbidity - towards a standard tool to measure and monitor maternal health beyond mortality. BMC Pregnancy Childbirth. 2016;16:45.

71. Say L, Chou D, Barbour K, Barreix M, Cecatti J, Costa M, et al. Maternal morbidity: time for reflection, recognition, and action. Int J Gynecol Obstet. 2018;141(S1):1-3.

72. Vanderkruik RC, Tunçalp Ö, Chou D, Say L. Framing maternal morbidity: WHO scoping exercise. BMC Pregnancy Childbirth. 2013;13:213.

73. Lange IL, Gherissi A, Chou D, Say L, Filippi V. What maternal morbidities are and what they mean for women: A thematic analysis of twenty years of qualitative research in low and lower-middle income countries. PLoS One. 2019;14(4):e0214199. Published 2019 Apr 11. https://doi.org/10.1371/journal. pone.0214199

74. McCauley M, Avais A, Agrawal R, Saleem S, Zafar S, van den Broek N. "Good health means being mentally, socially, emotionally and physically fit":
Women's understanding of health and ill-health during and after pregnancy. BMJ Open. 2020;10:e028760. https://doi.org/10.1136/bmjopen2018-028760.

\section{Publisher's Note}

Springer Nature remains neutral with regard to jurisdictional claims in published maps and institutional affiliations.
Ready to submit your research? Choose BMC and benefit from:

- fast, convenient online submission

- thorough peer review by experienced researchers in your field

- rapid publication on acceptance

- support for research data, including large and complex data types

- gold Open Access which fosters wider collaboration and increased citations

- maximum visibility for your research: over $100 \mathrm{M}$ website views per year

At BMC, research is always in progress.

Learn more biomedcentral.com/submissions 